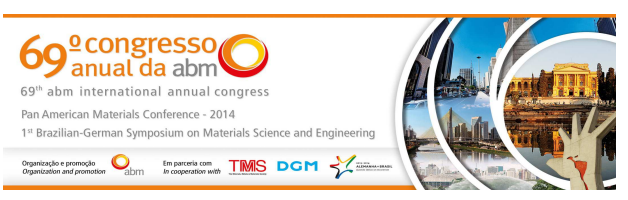

Tema: Engenharia de Superfície

\title{
EFEITO DA TEMPERATURA NO ALÍVIO DE TENSÕES RESIDUAIS PRESENTES NA CAMADA NITRETADA*
}

\author{
Cristiane Sales Gonçalves ${ }^{1}$ \\ André Paulo Tschiptschin ${ }^{2}$ \\ Paulo Haddad ${ }^{3}$
}

\section{Resumo}

O processo de injeção sob pressão de ligas de alumínio é empregado para a produção de peças diversas, destinadas principalmente à indústria automobilística, com a possibilidade de produzir peças complexas, contendo seções delgadas, e a alta velocidade de produção. $O$ reduzido tempo de ciclo e as elevadas temperaturas envolvidas promovem danos por fadiga térmica na superfície de trabalho das matrizes, que crescem com o aumento da produção até atingirem condições que inviabilizam o uso da matriz. O presente trabalho visou estudar o efeito da nitretação na superfície do material, relacionando-o aos aspectos microestruturais e tensões residuais inseridas durante nitretação. O aço AISI H13, foi tratado para dureza de $45 \mathrm{HRC}$ e posteriormente nitretado sob plasma em diversas condições de temperatura, tempo e composição da atmosfera gasosa. Os resultados obtidos mostraram que as variações dos parâmetros de nitretação afetam os perfis de dureza e de tensões residuais presentes nas camadas nitretadas, bem como os microconstituintes das mesmas. O material nitretado, após ser submetido a temperaturas da ordem de $600^{\circ} \mathrm{C}$, apresentou redução no nível de tensões residuais de compressão, ocorrendo processo de alívio de tensões. O mesmo efeito não foi tão fortemente verificado no perfil de dureza do material.

Palavras-chave: Nitretação sob plasma; Injeção sob pressão de alumínio; Fadiga térmica; Tensões residuais.

\section{THE EFFECT OF TEMPERATURE ON THE RESIDUAL STRESS RELIEF PRESENTS IN NITRED LAYER}

\begin{abstract}
The process of pressured injection of aluminum alloys is made use of in the production of sundry parts, meant mainly for the automotive industry, among the main advantages of such process there stands out the possibility of production of complex parts, with thin sections, and at a high output speed. The reduced cycle time and high temperatures involved cause damage due to the thermal fatigue on the working surface of dies. The present paper has aimed at studying the nitrinding effect on material surface by relating it to the microstructural aspects of the surface, residual tensions inserted during the nitriding process. AISI H13 were quenched and tempered to hardness in $45 \mathrm{HRC}$ and later subjected to plasma nitriding in different conditions of temperature, time, and gas atmosphere composition. Results obtained have shown that the variation of nitriding parameters, such as time, temperature, and nitrogen percent, affect the hardness and residual tension profiles present in the surface nitriding, as well as in its microcomponents. The resulting material, after being subjected to high temperature, presents a reduction of level in the residual tensions of compression, bringing about a process of tensions relief. The same effect is not so strongly verified in the material hardness profile.
\end{abstract}

Keywords: Plasma nitriding; Pressured aluminum injection; Thermal fatigue; Residual stress.

1 Engenheira de Materiais, Msc. Engenharia Metalúrgica e de Materiais, Eng ${ }^{a}$ de Aplicação e Assessora Técnica, Villares Metals SA, Sumaré, SP, Brasil.

2 Engenheiro Metalurgista, Dr. Engenharia Metalúrgica e de Materiais, Professor, Departamento de Engenharia Metalúrgica e de Materiais, Escola Politécnica, USP, São Paulo, SP, Brasil.

3 Engenheiro Metalurgista, Msc. Engenharia Metalúrgica e de Materiais, Gerente Eng ${ }^{a}$ de Aplicação e Assessora Técnica, Villares Metals SA, Sumaré, SP, Brasil.

\footnotetext{
* Contribuição técnica ao $69^{\circ}$ Congresso Anual da ABM - Internacional e ao 14ํㅡㄹ ENEMET - Encontro Nacional de Estudantes de Engenharia Metalúrgica, de Materiais e de Minas, 21 a 25 de julho de 2014, São Paulo, SP, Brasil.
} 


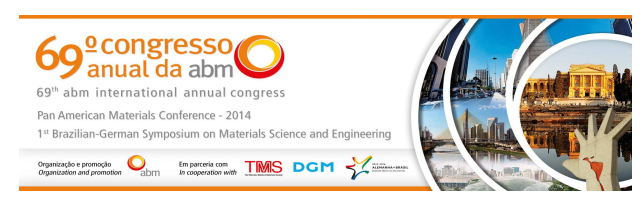

\section{INTRODUÇÃO}

Os aços especiais para ferramentas industriais ficam sujeitos a esforços repetitivos muito elevados, trabalhando em condições extremas, e têm como destino inevitável falhar. A falha ocorrerá de maneira mais lenta, ou mais rápida, dependendo de diversos fatores que se definem desde o projeto das ferramentas e escolha do aço, passando pelo processo de manufatura e finalmente pelas condições de operação. Independentemente de se estimar a vida útil de uma ferramenta em milhares ou centenas de milhares de peças produzidas, economicamente existe um ponto de equilíbrio que, em média, deve ser superado para que o negócio seja lucrativo [1]. 0 ambiente competitivo faz este valor, o ponto de equilíbrio, constantemente ser puxado para números maiores. Um exemplo interessante é a fundição de peças de alumínio para a indústria automobilística, mais especificamente, a fundição sob pressão. A vida da matriz de injeção é determinada pelo tempo de produção, em ritmo normal de trabalho em ciclagem térmica, produzindo peças sem defeitos, o que torna constante a necessidade do desenvolvimento de materiais avançados para estas aplicações [2,3] Diante do exposto, começam os desafios de como aumentar a vida útil de uma ferramenta. Os desafios não são simples, visto que ao mesmo tempo em que se procura melhorar a longevidade do ferramental também se agravam as condições de projeto e operação, buscando-se peças de maior complexidade e menor peso e maior produtividade. Nestes casos, por exemplo, detalhes mais complexos implicam o uso de maiores temperaturas de injeção, aumentando o dano térmico à matriz [2].

Os aços que são empregados na confecção das matrizes de fundição sob pressão de ligas leves vêm sendo melhorados de forma a retardar os mecanismos típicos de falha. Os aços da série $\mathrm{H}$, do tipo $\mathrm{H} 13$ ou $\mathrm{H} 11$, com algumas modificações, tais como redução de $\mathrm{Si}$ e $\mathrm{P}$, vem ganhando mercado e demonstrando o seu desempenho superior em aplicações cada vez mais severas [4].

A seleção do tipo do aço, nestes casos, é complexa. Mas o emprego do melhor dos aços é apenas um dos fatores e isoladamente não poderá garantir a melhoria necessária de vida útil das ferramentas. São necessários outros cuidados que se estendem também às áreas de projeto (produto/ferramenta), processo de fabricação das ferramentas, operação de produção (processo de injeção), manuseio das ferramentas e tratamento térmico.

Este cenário para ferramentas de trabalho motiva a contínua melhoria, em relação a todos os fatores que interagem em sua aplicação. Especificamente em relação ao tratamento térmico aplicado, existe uma constante evolução, em termos de melhorias do processo e parâmetros empregados, buscando maximizar o desempenho do ferramental. Para retardar os danos na superfície do molde, gerados naturalmente pelo processo de injeção do alumínio, processos de tratamentos termoquímicos sob plasma como a nitretação são utilizados para melhorar as propriedades superficiais.

O processo de nitretação promove o aumento na dureza da camada superficial melhorando as características tribológicas, tais como propriedades mecânicas da superfície, como dureza, fadiga e fricção, além da resistência à erosão/ataque do alumínio, podendo propiciar ainda um aumento da vida útil das peças tratadas [5]. $O$ processo de nitretação sob plasma permite controlar a metalurgia da superfície nitretada de acordo com o tipo de aço e aplicação do ferramental. Com o controle dos principais parâmetros de processo, temperatura, tempo e composição da

\footnotetext{
* Contribuição técnica ao 69 Congresso Anual da ABM - Internacional e ao $14^{\circ}$ ENEMET - Encontro Nacional de Estudantes de Engenharia Metalúrgica, de Materiais e de Minas, 21 a 25 de julho de 2014, São Paulo, SP, Brasil.
} 


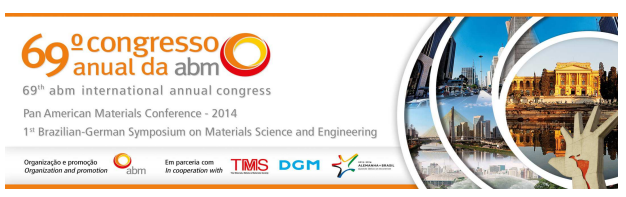

mistura gasosa, é possível gerar superfícies sem camada de compostos, ou seja, formadas apenas pela zona de difusão, e controlar a profundidade de endurecimento. A camada nitretada formada durante o tratamento possui uma influência positiva na vida em fadiga térmica de um componente/ferramenta, graças a dois motivos principais [6]: o primeiro é o atraso na nucleação da trinca devido ao aumento da resistência mecânica superficial, uma vez que uma maior dureza resulta em menor sensibilidade à deformação plástica e, portanto, maior a resistência ao início da fadiga térmica; o segundo motivo está relacionado com a introdução de tensões residuais compressivas durante o processo de endurecimento da superfície, que retarda a iniciação da trinca, diminuindo a tensão efetiva na ponta do defeito [7].

\subsection{Revisão Bibliográfica}

\subsubsection{Falhas em matrizes para fundição sob pessão de alumínio}

Os aços para matrizes de fundição de alumínio requerem não somente propriedades mecânicas adequadas como resistência e dureza, mas também elevada tenacidade, limite de resistência ao escoamento a quente, resistência a quente e ductilidade [8]. Os aços ferramenta para trabalho a quente com adequado nível de ductilidade, dureza e tenacidade, possuem maior vida útil em matrizes devido à capacidade de deter o processo de início e crescimento de trinca por fadiga térmica [9]. Uma propriedade importante a se considerar para o aço do molde é a "resistência à fratura" que mede a resistência à propagação de uma trinca [10]. Quando a matriz está em trabalho, a zona mais quente está localizada na superfície da cavidade de trabalho e, se houver uma trinca já nucleada, esta resistirá mais à propagação se o material apresentar alta tenacidade à fratura, podendo se propagar mais rápido somente se a temperatura e tensões aumentarem. Também se tornam importantes propriedades físicas, tais como condutividade térmica e coeficiente de expansão gerada pelo aquecimento, respectivamente. $\mathrm{O}$ aumento destas propriedades diminui, assim, as tensões de fadiga de origem térmica.

Apesar de estes diversos aspectos serem importantes, a maioria das falhas (prematuras ou esperadas) pode ser entendida baseada em duas propriedades principais: (a) relativa à resistência a quente e ao revenido; (b) relativas à tenacidade do aço ferramenta. Obviamente, a falha da ferramenta possui como fator fundamental, também, as questões de projeto, tratamento térmico e utilização das ferramentas e estas variáveis acabam demandando do aço ferramenta uma maior resposta em termos de tenacidade ou resistência a quente, que pode ou não ser suficiente. Uma vez excedida a capacidade do material, a falha ocorrerá [6].

Deste modo existem inúmeros fenômenos que restringem a vida útil da matriz. Os mais importantes são [6,11]:

- Fadiga térmica (trincas térmicas);

- Erosão

- Ataque do alumínio (corrosão);

- Trincas catastróficas (falha total).

Um dos principais danos que ocasionam o fim da vida útil de uma matriz de fundição de alumínio é o desenvolvimento prematuro de uma malha de trincas térmicas, que comprometem a qualidade superficial da peça produzida [12-14]. A geração destas trincas faz com que, durante processo, haja impregnação do alumínio líquido nas frestas existentes, deixando relevo na peça injetada e dificultando a extração da mesma. A fadiga térmica pode ser basicamente descrita como uma trinca gradual

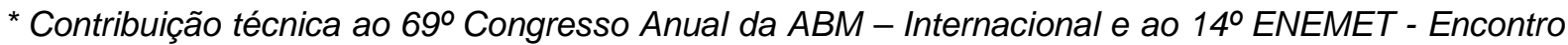
Nacional de Estudantes de Engenharia Metalúrgica, de Materiais e de Minas, 21 a 25 de julho de 2014, São Paulo, SP, Brasil.
} 


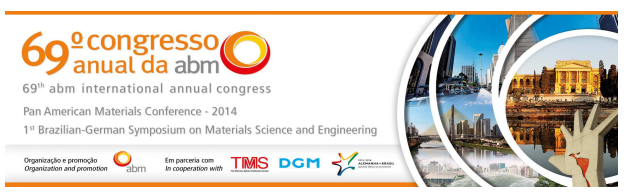

causada pela ciclagem térmica (exposição cíclica ao calor e ao resfriamento), devido a muitos ciclos térmicos, causada principalmente pela diferença de expansão quando o metal é aquecido e de contração quando o material é esfriado alternadamente, o que ocasiona tensões de tração e compressão, gerando a fadiga $[3,13,15]$. Isto causa um aumento severo das tensões na camada superficial da matriz, conduzindo gradualmente para a formação de trinca por fadiga térmica. É um fenômeno em microescala que ocorre somente em uma fina camada superficial [16].

\subsubsection{Estudos de fadiga térmica em aços nitretados}

Conforme discutido nos itens anteriores, a fadiga térmica representa um dos mais importantes modos de falha que surgem durante o processo de fundição sob pressão de alumínio [6]. Para aumentar a vida útil da matriz, muitos estudos foram realizados, principalmente sobre a escolha correta do tipo e qualidade do aço, tratamento térmico e, recentemente, tipos de tratamento de superfície [11]. A extensão da vida útil não somente reduz o custo de produção de cada peça injetada, como também eleva o nível de produtividade. Alguns dos benefícios do processo de nitretação sob plasma já foram estudados, principalmente os relacionados ao aumento da resistência ao degaste/adesão e resistência à fadiga mecânica [17]. Nestes estudos verificou-se que a elevação da dureza superficial e a presença de tensões residuais de compressão atuavam beneficamente para retardar a nucleação de trincas, erosão/ataque do alumínio e desgaste nas regiões dos canais de alimentação. Poucos estudos foram realizados para mensurar o impacto que 0 processo de nitretação proporciona na resistência a fadiga térmica [6]. Spies [7] comentou em seu trabalho que materiais nitretados contendo camada de compostos não apresentavam bons desempenhos quando submetidos à ciclagem térmica, uma vez que a camada de compostos era responsável por facilitar a nucleação de trincas, devido à sua natureza frágil. Spies [7] concluiu que a resistência à fadiga térmica em materiais nitretados seria determinada pela tenacidade, espessura da camada nitretada, ausência de camada de compostos e do estado de tensões existentes na camada nitretada. O estado de tensões residuais de compressão combinado com o aumento da resistência a quente da camada de difusão eram base para o incremento da resistência a fadiga térmica [7].

A base dos processos de nitretação e de recobrimentos para aumentar a resistência à fadiga térmica está relacionada ao elevado nível de tensões residuais de compressão inserido na superfície do material durante processo de nitretação ou de recobrimento, e à alta dureza a quente que retardam a nucleação e crescimento das trincas. Adicionalmente, Pellizzari [6,15] observou que falhas prematuras em camadas nitretadas ou revestidas, quando submetidas à ciclagem térmica, devem-se também à diferença de coeficientes de expansões térmicas existentes entre a superfície modificada e o material base, principalmente quando a diferença de temperaturas for grande [17].

\subsubsection{Tensão residual em peças nitretadas}

A literatura sugere que a nitretação atinge uma considerável profundidade de endurecimento e gera tensões residuais compressivas [18-21]. A presença de tensões residuais compressivas na superfície de um componente é um fator que reduz a chance de iniciação de trincas de fadiga mecânica e, consequentemente, de fadiga térmica [22]. As principais causas de tensões residuais estão ligadas a

\footnotetext{
* Contribuição técnica ao 69 Congresso Anual da ABM - Internacional e ao 14ํㅡㄹ ENEMET - Encontro Nacional de Estudantes de Engenharia Metalúrgica, de Materiais e de Minas, 21 a 25 de julho de 2014, São Paulo, SP, Brasil.
} 


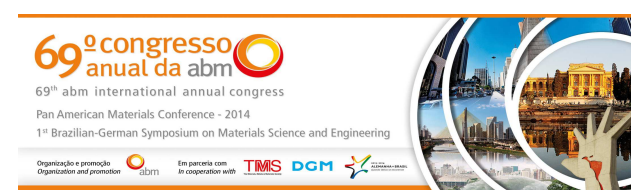

variações volumétricas na camada superficial da peça nitretada devido aos seguintes fatores [18-21]:

(a) Tensões elásticas na rede.

- Nitrogênio difundido na matriz - distorção da rede cristalina;

- Precipitação de diferentes nitretos na camada de difusão - os nitretos formados possuem volume molar (tamanho, forma e tipo de interface) maior que a matriz;

- Formação de nitretos de ferro na camada de compostos;

- Descarbonetação da camada de difusão promovida pela entrada de nitrogênio durante nitretação.

(b) Tensões que surgiram no resfriamento, devido à diferença de expansão térmica.

- Diferenças de contração térmica entre a camada nitretada e o substrato durante o resfriamento;

- Diferentes coeficientes de expansão térmica entre os precipitados e a matriz.

Portanto, as tensões residuais aumentam com o aumento do teor de nitrogênio, devido ao maior número e volume dos precipitados formados.

A composição do material e os parâmetros do processo influenciam a ocorrência de tensões residuais no aço nitretado. A composição química do aço influencia não apenas a formação dos precipitados, como também o distribuição do nitrogênio na camada de difusão. Aços contendo grande quantidade de elementos fortemente formadores de nitretos, tais como alumínio, cromo, e titânio, além de formar uma camada nitretada de elevada dureza também promovem elevada tensão residual. Existe uma correlação entre a dureza e o nível de tensão residual da camada. Além disso, quanto maior o teor de carbono, maior o nível de tensões residuais compressivas [18].

A temperatura de nitretação tem importante efeito sobre as tensões residuais, pois influencia a taxa de difusão e a formação de precipitados [18]. Medidas de tensão residual durante o processo de nitretação revelaram importantes valores não só da relaxação da tensão, mas da deformação plástica durante a nitretação; além disso, os parâmetros do processo introduzem tensões residuais na camada composta e de difusão. $O$ processo de resfriamento pode ser considerado um importante passo na geração das tensões residuais na camada composta, em virtude das tensões criadas na camada de difusão durante a nitretação. A temperatura tem forte influência no perfil de tensões residuais desenvolvidas durante nitretação; quanto menor a temperatura maior são as tensões de compressão e mais próximas da superfície. Aumentando a temperatura o nível de tensões de compressão diminui, porém a profundidade que apresenta tensões de compressão aumenta.

O tempo de nitretação também influencia o perfil de tensões residuais. Longos tempos de nitretação resultam numa redução dos valores de tensão residual para todas as distâncias a partir da superfície, e no deslocamento do valor máximo de tensão residual de compressão para mais longe da superfície. O processo simultâneo de geração e relaxação de tensões explica este fenômeno, pois a relaxação predomina em tempos mais longos de tratamento. A distância, a partir da superfície, na qual a tensão residual torna-se nula, também é aumentada, indicando o crescimento da camada de difusão $[19,20]$.

\footnotetext{
* Contribuição técnica ao 69 Congresso Anual da ABM - Internacional e ao $14^{\circ}$ ENEMET - Encontro Nacional de Estudantes de Engenharia Metalúrgica, de Materiais e de Minas, 21 a 25 de julho de 2014, São Paulo, SP, Brasil.
} 


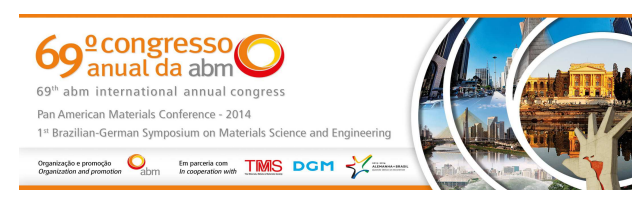

\subsection{Objetivos}

O objetivo deste trabalho foi avaliar a resposta a nitretação do aço AISI H13 empregado nas matrizes de injeção sob pressão de alumínio em termos da dureza, tensões residuais e a estabilidade da camada nitretada em altas temperaturas.

\section{MATERIAIS E METODOS}

Amostras em aço AISI H13 foram temperadas e revenidas para dureza média de 45 HRC e caracterizadas microestruturalmente. Posteriormente foram nitretadas sob plasma, empregando diferentes tempos, temperaturas e atmosferas gasosas, e avaliadas através de medições de tensões residuais, perfil de microdureza e difração de raios- $X$.

A composição química do material estudado encontra-se na Tabela 1.

Tabela 1: Composição química do material estudado. Porcentagem em massa e balanço em Fe.

\begin{tabular}{c|c|c|c|c|c|c|c|c|c|c}
\hline Aço & Similaridade & C & Si & P & S & Mn & Cr & Mo & V & Ni \\
\hline VH13ISO $^{\circledast}$ & AISI H13 & 0,38 & 0,95 & 0,024 & 0,001 & 0,37 & 5,17 & 1,28 & 0,84 & 0,16 \\
\hline
\end{tabular}

A Tabela 2 apresenta os ciclos de nitretação realizados. Conforme pode ser observado nesta tabela, a pressão, tensão entre os eletrodos, tempo de pulso e tempo de parada do pulso foram mantidos constantes para todas as condições.

Tabela 2: Parâmetros utilizados na nitretação das amostras.

\begin{tabular}{l|l}
\hline Tempo & $31 / 2,6$ e $81 / 2$ horas \\
\hline Temperatura & 480,520 e $5600^{\circ} \mathrm{C}$ \\
\hline Atmosfera Gasosa & $5 \% \mathrm{~N}_{2} 95 \% \mathrm{H}_{2}, 20 \% \mathrm{~N}_{2} 80 \% \mathrm{H}_{2}$ e $40 \% \mathrm{~N}_{2} 60 \% \mathrm{H}_{2}$ \\
\hline Pressão & $3,5 \mathrm{mbar}$ \\
\hline Tensão entre os eletrodos & $520 \mathrm{~V}$ \\
\hline Duração do pulso & $100 \mu \mathrm{s}$ \\
\hline Tempo de parada do pulso & 500 \\
\hline
\end{tabular}

Algumas das amostras foram submetidas ao ciclo de nitretação a $520^{\circ} \mathrm{C}$, por 6 horas e atmosfera gasosa de $20 \% \mathrm{~N}_{2}+80 \% \mathrm{H}_{2}$, e posteriormente expostas à temperatura de $600^{\circ} \mathrm{C}$ por tempos de 30 minutos, 2, 5, 10 e 100 horas, para avaliar como as tensões residuais presentes na camada nitretada seriam aliviadas quando submetidas em elevada temperatura e por tempos longos. Uma amostra foi conservada para estudo das tensões residuais iniciais da peça.

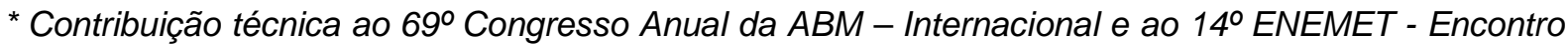
Nacional de Estudantes de Engenharia Metalúrgica, de Materiais e de Minas, 21 a 25 de julho de 2014, São Paulo, SP, Brasil.
} 


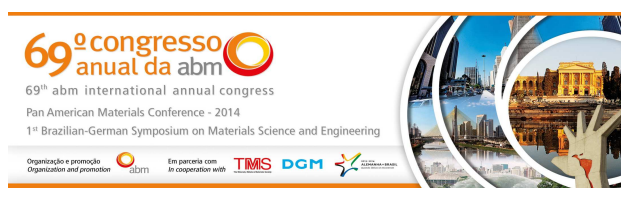

Figura 1: Comparativo das microestruturas obtidas para os diferentes parâmetros de nitretação para o aço AISI H13.

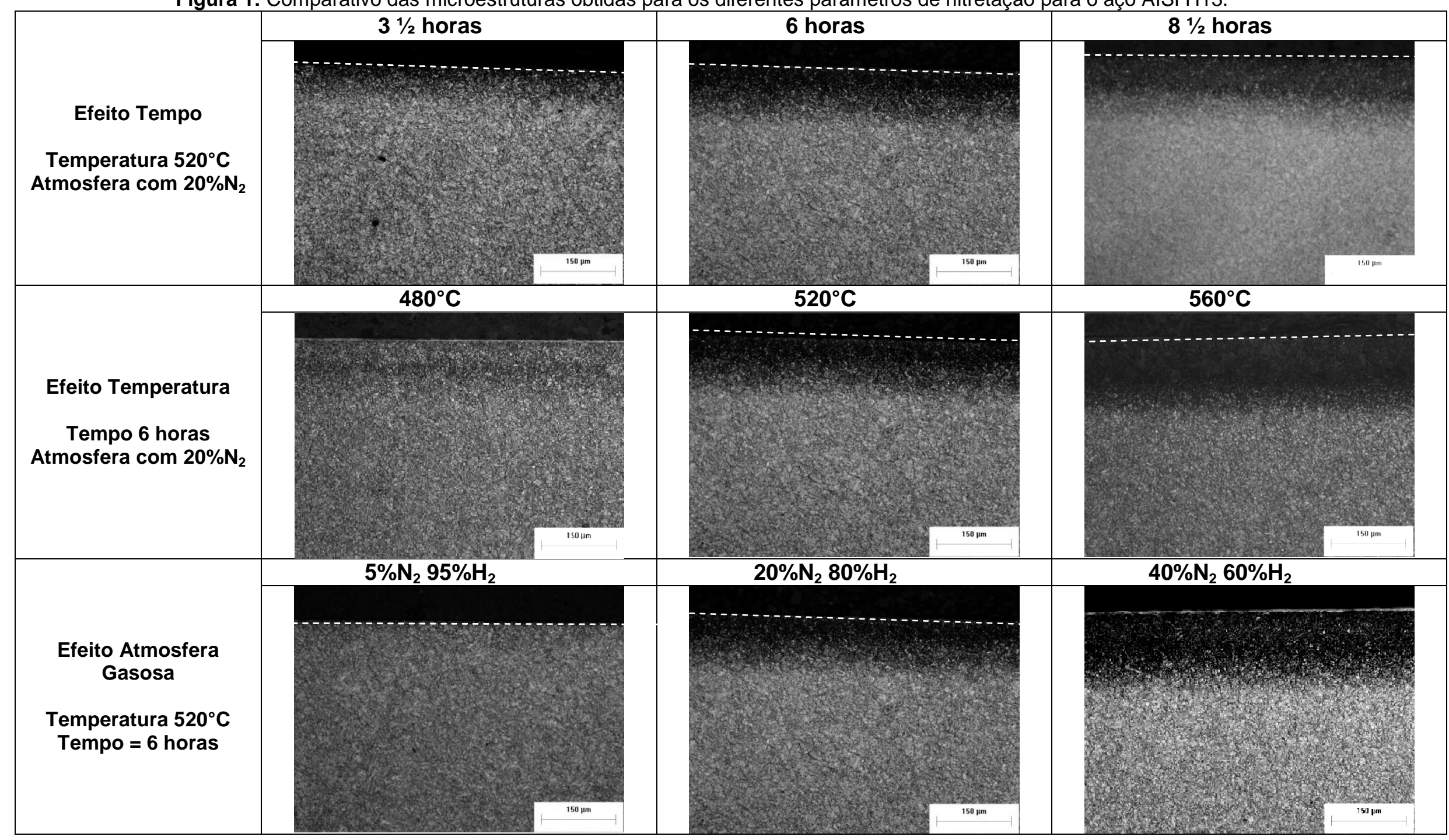

* Contribuição técnica ao 69 Congresso Anual da ABM - Internacional e ao 14ํㅡㄹ ENEMET - Encontro Nacional de Estudantes de Engenharia Metalúrgica, de Materiais e de Minas, 21 a 25 de julho de 2014, São Paulo, SP, Brasil. 


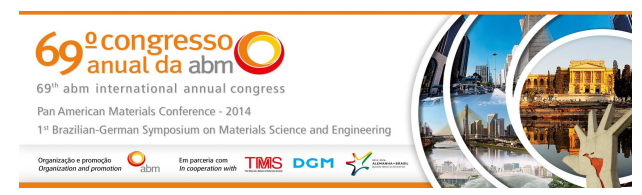

\section{RESULTADOS E DISCUSÕES}

\subsection{Caracterização Microestrutural}

As micrografias das camadas nitretadas para as condições de nitretação estudadas são apresentadas na Figura 1. A análise das micrografias revela a presença uma camada superficial de coloração escura composta por finos nitretos de ferro e de elementos de liga e uma região na qual existe um gradiente de concentração de nitrogênio intersticial que diminui em direção ao material base. Estas regiões compõem a camada de difusão. A amostra nitretada a $480^{\circ} \mathrm{C}$ por 6 horas, a amostra nitretada a $520^{\circ} \mathrm{C}$ por 8,5 horas e a amostra nitretada com $40 \%$ de nitrogênio possuem camadas de compostos. Somente a amostra nitretada com elevado teor de nitrogênio (40\%) apresentou formação de filmes de nitretos contínuos em contornos de grãos. A microestrutura do material é martensita revenida resultante do tratamento térmico de têmpera e revenimento.

\subsection{Perfis de Microdureza}

Os perfis de microdureza obtidos para cada um dos materiais, para cada condição de nitretação, são apresentados nas Figuras 2 a 4. Através do perfil de microdureza é possível determinar a espessura da camada nitretada, mediante a profundidade afetada pelo aumento de dureza característico desta camada. Os valores de dureza estabilizam-se em torno de 450-500 HV, em média. Portanto, considerou-se $600 \mathrm{HV}$ como um valor no qual houve significativo aumento de dureza relativo à formação da camada nitretada. Nos perfis de microdureza relativos à nitretação de 3,5 horas, nota-se que, de modo geral, as camadas obtidas são de elevada dureza, porém pouco espessas. Logo abaixo da superfície os valores são bastante elevados, decaindo rapidamente à medida que a profundidade aumenta. De modo geral, para os tratamentos de 6,0 e 8,5 horas, os picos de dureza são um pouco menores, porém, a profundidade da camada endurecida é maior.

VH13ISO 8 - Nitretado a $520^{\circ} \mathrm{C}-20 \% \mathrm{~N} 2+80 \% \mathrm{H} 2$

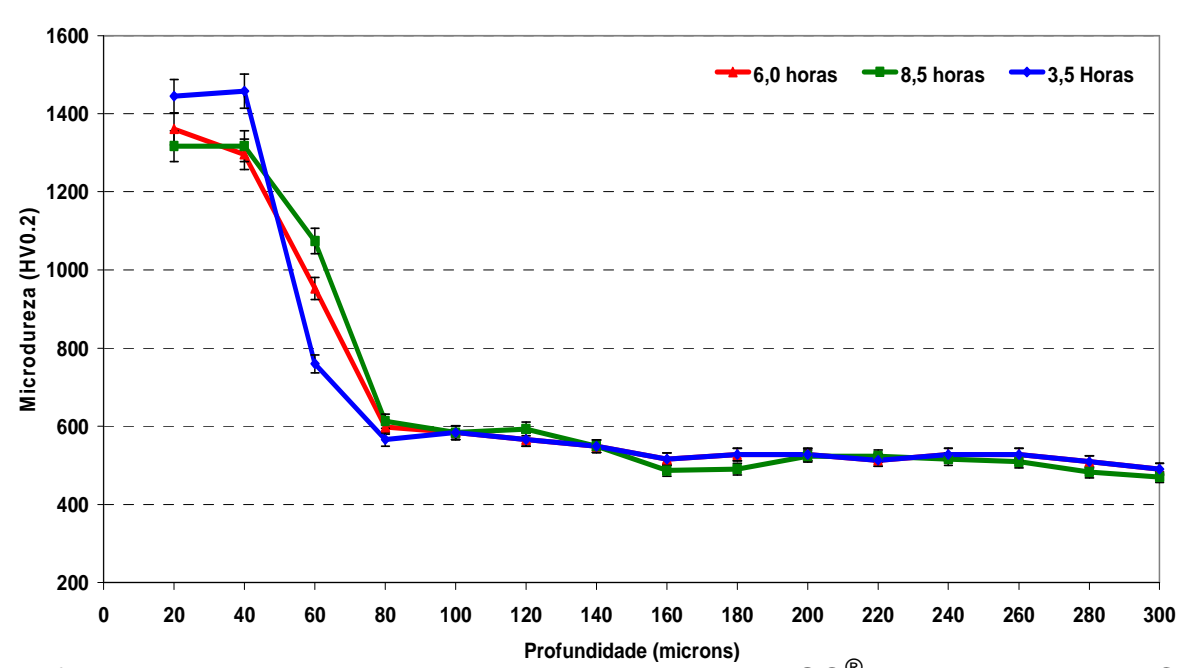

Figura 2: Perfil de microdureza obtido para o aço $\mathrm{VH} 13 \mathrm{ISO}{ }^{\circledR}$ nitretado a $520^{\circ} \mathrm{C}$, composição atmosfera gasosa $20 \% \mathrm{~N}_{2}+80 \% \mathrm{H}_{2}$.

* Contribuição técnica ao 69ํCongresso Anual da ABM - Internacional e ao 14 ENEMET - Encontro Nacional de Estudantes de Engenharia Metalúrgica, de Materiais e de Minas, 21 a 25 de julho de 2014, São Paulo, SP, Brasil. 


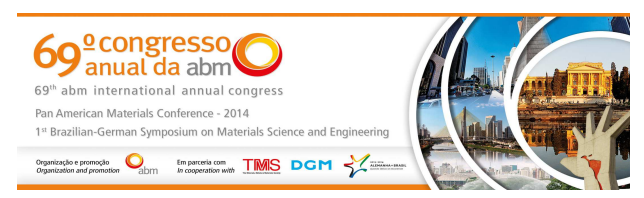

VH13ISO $\circledast$ - nitretado por 6 horas - $20 \% \mathrm{~N} 2+80 \% \mathrm{H} 2$

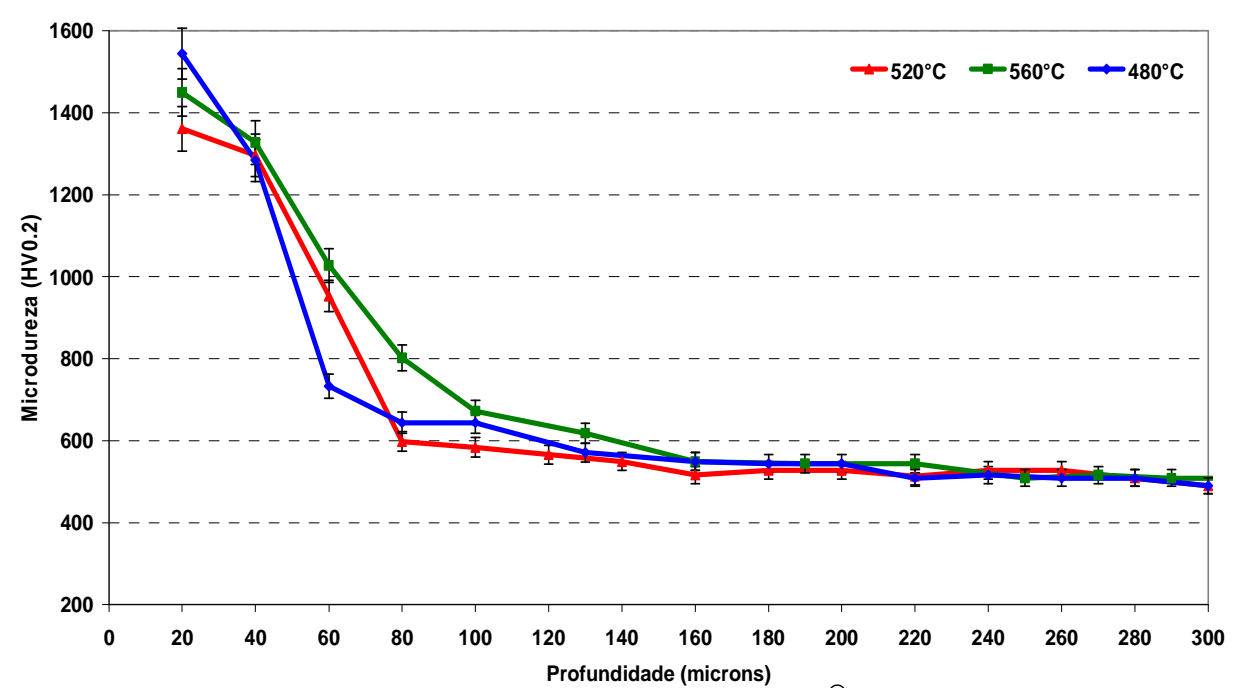

Figura 3: Perfil de microdureza obtido para o aço $\mathrm{VH} 131 \mathrm{SO}^{\circledR}$ nitretado por 6 horas, composição atmosfera gasosa $20 \% \mathrm{~N}_{2}+80 \% \mathrm{H}_{2}$.

Ao se analisar o efeito da temperatura no perfil de microdureza da camada nitretada, nota-se que a profundidade da camada nitretada é tanto maior quanto maior a temperatura de processo. Do mesmo modo, nota-se que o patamar elevado de dureza, relativo à camada de difusão, decresce mais lentamente. Também foi possível verificar que quanto maior a quantidade de nitrogênio inserido no processo, mais profunda fica a camada de difusão da camada nitretada. Também pode ser observado que a utilização de $5 \%$ de nitrogênio foi pouco efetivo para o processo de nitretação, resultando em uma camada nitretada com baixa dureza.

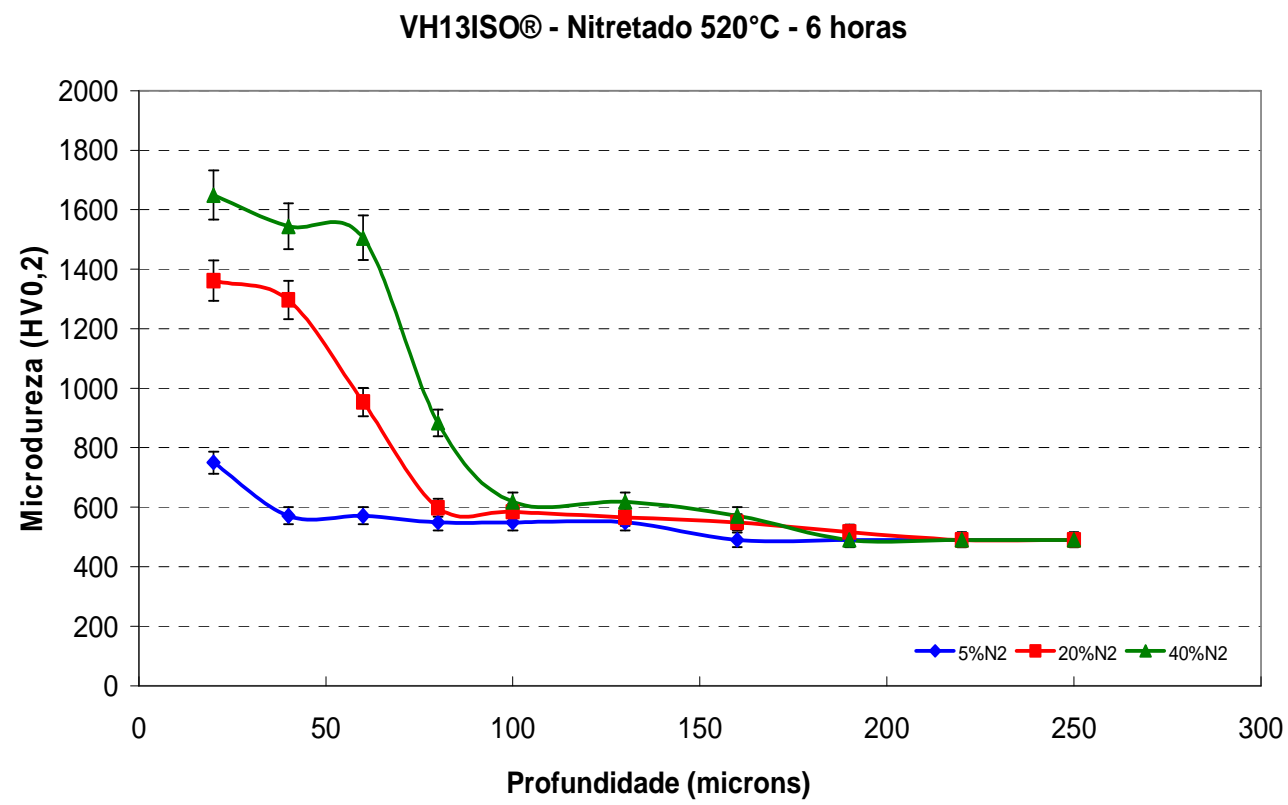

Figura 4: Perfil de microdureza obtido para o aço $\mathrm{VH} 13 \mathrm{ISO}{ }^{\circledR}$ nitretado por 6 horas, temperatura de $520^{\circ} \mathrm{C}$, em diferentes concentrações de nitrogênio.

* Contribuição técnica ao 69 Congresso Anual da ABM - Internacional e ao 14ํㅡㄹ ENEMET - Encontro Nacional de Estudantes de Engenharia Metalúrgica, de Materiais e de Minas, 21 a 25 de julho de 2014, São Paulo, SP, Brasil. 


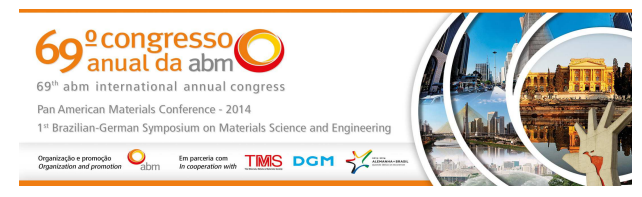

\subsection{Tensão Residual}

Os perfis de tensões residuais obtidos são apresentados nas Figuras 5 a 7 . Ao estudar o efeito do tempo, Figura 5, nota-se uma elevada tensão compressiva na superfície, cerca de 900-1000 MPa, sendo que o valor máximo desta tensão encontra-se deslocado para o interior da amostra em maior ou menor grau, dependendo do tempo de nitretação. A partir dos perfis apresentados, observa-se que as tensões compressivas não ultrapassam $100 \mu \mathrm{m}$ de profundidade e os valores máximos compressivos de tensões situam-se entre 40 e $60 \mu \mathrm{m}$. De um modo geral, ao se aumentar o tempo de nitretação, o pico compressivo de tensão se desloca para o interior do material, embora esse deslocamento seja pequeno. Pode-se supor que as tensões residuais de compressão são resultantes das distorções ocorridas na rede cristalina do material durante processo de precipitação de nitretos que possuem volume, forma, distribuição e interface diferente da matriz do substrato. Próximo à superfície, as tensões são mais baixas, pois o teor de carbono local é menor, devido à redistribuição de carbono promovida pela entrada de nitrogênio durante nitretação.

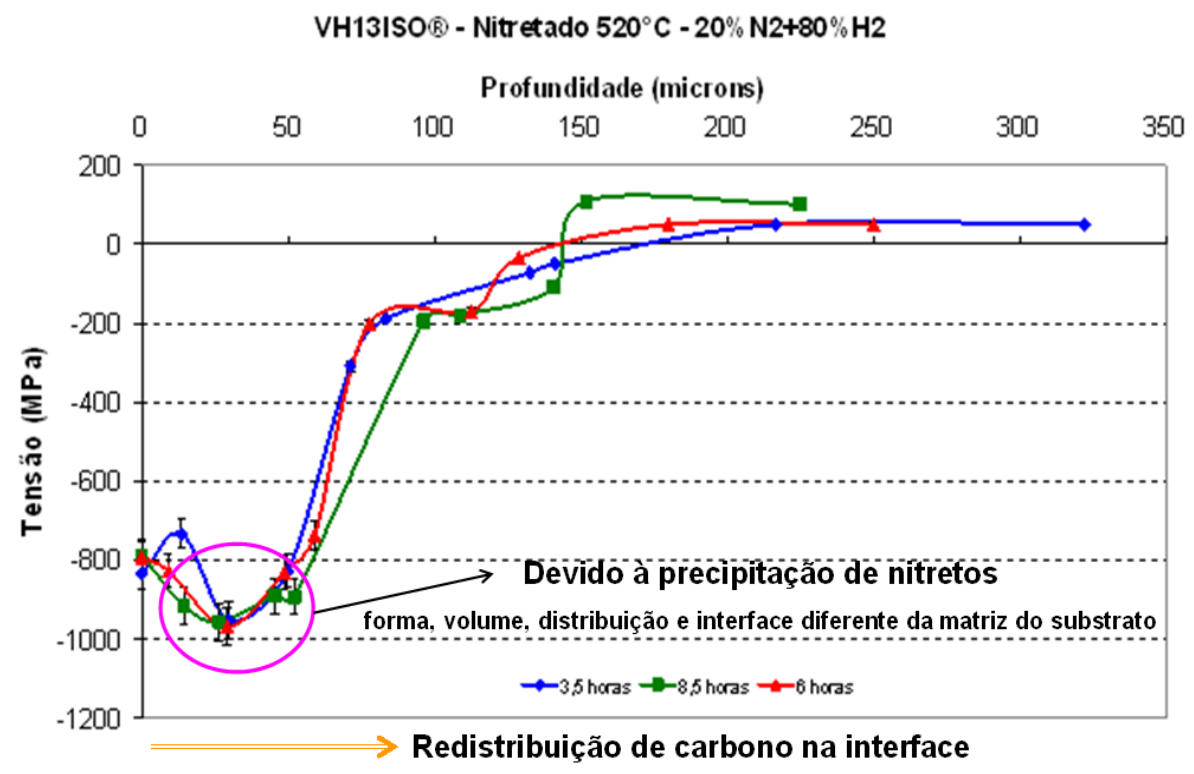

Figura 5: Influência do tempo nas tensões residuais - aço VH13ISO - nitretado a $520^{\circ} \mathrm{C}$, composição atmosfera gasosa $20 \% \mathrm{~N}_{2}+80 \% \mathrm{H}_{2}$.

Nota-se no estudo do efeito da temperatura no perfil de tensão residual, Figura 6, da camada nitretada uma elevada tensão de compressão na superfície, sendo esta tanto mais intensa, quanto menor a temperatura de processo. O valor máximo desta tensão encontra-se deslocado para o interior da amostra em maior grau conforme ocorre o aumento da temperatura. A partir dos perfis apresentados, observa-se que o máximo das tensões compressivas, para a temperatura de $480^{\circ} \mathrm{C}$, está localizado próximo à superfície e a intensidade das tensões residuais compressivas cai mais rapidamente ao se comparar com as curvas dos processos realizados as temperaturas de 520 e $560^{\circ} \mathrm{C}$.

Pela análise da Figura 6, observa-se um efeito interessante: para a temperatura de nitretação de $480^{\circ} \mathrm{C}$, o valor de tensão residual no fundo do poço ficam entre -2500 a - $2000 \mathrm{MPa}$, sendo esse valor muito próximo do previsto pela literatura (Vide

* Contribuição técnica ao 69ํCongresso Anual da ABM - Internacional e ao 14 ENEMET - Encontro Nacional de Estudantes de Engenharia Metalúrgica, de Materiais e de Minas, 21 a 25 de julho de 2014, São Paulo, SP, Brasil. 


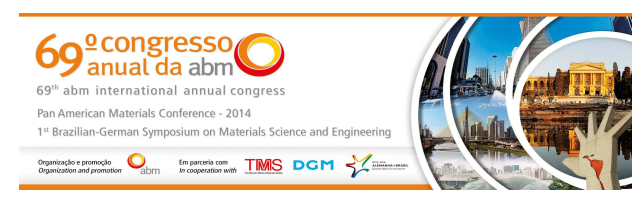

Tabela 3), quando ocorre formação de nitretos do tipo $\mathrm{Fe}_{4} \mathrm{~N}$ na camada de compostos, pois durante o processo de resfriamento, a contração volumétrica da camada branca é maior comparativamente à camada de difusão e substrato, introduzindo maior nível de tensões residuais de compressão [18]. No caso da nitretação a $480^{\circ} \mathrm{C}$ tanto a formação de camada de compostos na superfície quanto a precipitação de nitretos na matriz do material, contribuem para o elevado nível de tensões de compressão, uma vez que o volume molar do nitreto é maior que a matriz, o que irá proporcionar maior grau de distorção da rede cristalina, aumentando, assim, o nível de tensão residual compressiva. Nas temperaturas de $520^{\circ} \mathrm{C}$ e $560^{\circ} \mathrm{C}$ as tensões são devidas somente à precipitação de nitretos na matriz, pois não há formação de camada de compostos.

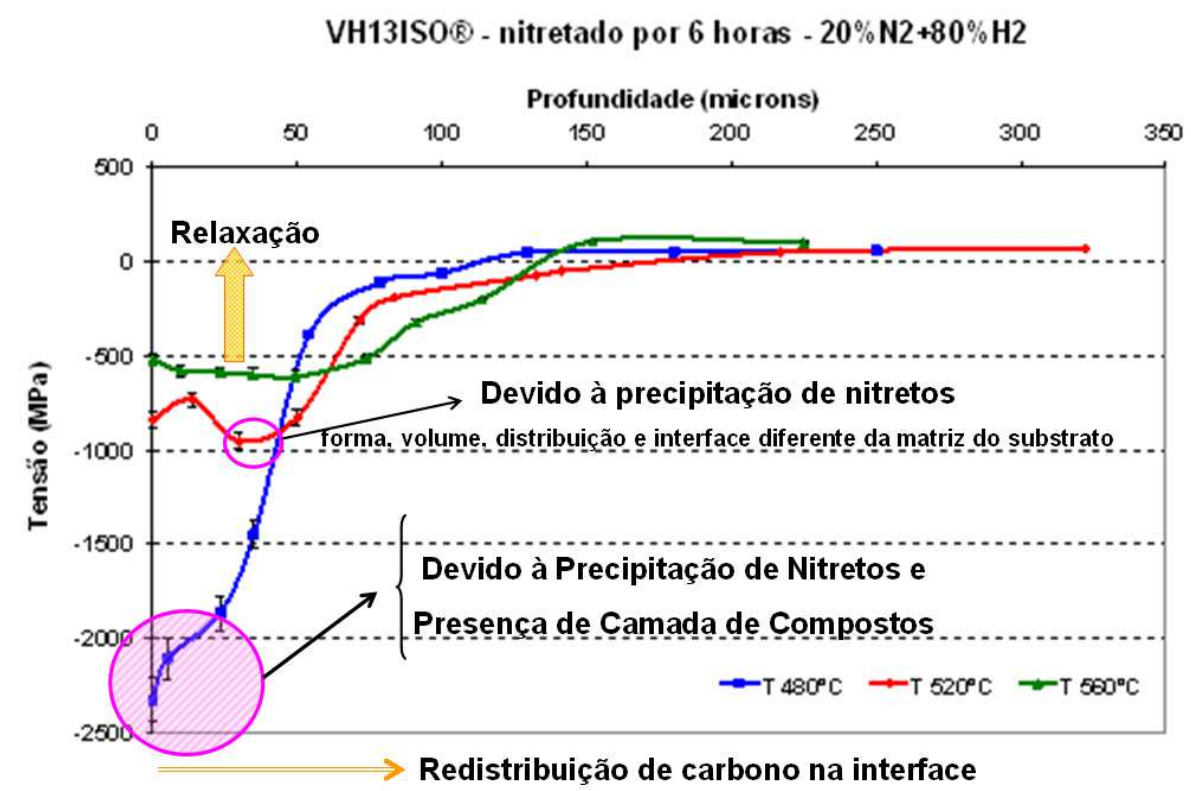

Figura 6: Influência da temperatura nas tensões residuais - aço VH13ISO - nitretado por 6 horas, composição atmosfera gasosa $20 \% \mathrm{~N}_{2}+80 \% \mathrm{H}_{2}$.

Considerando a temperatura de $560^{\circ} \mathrm{C}$, ao ocorrerem as precipitações dos nitretos, 0 nível de tensão na camada superficial irá aumentar, devido a distorção da rede, ocasionada pela quantidade, volume, distribuição dos nitretos formados. Mas neste caso, devido à temperatura empregada no processo, irá ocorrer alívio de tensões (relaxação) e coalescimento dos precipitados, reduzindo o grau de distorção da rede, o que resultará em menores profundidades de poço de tensões residuais, como os encontrados neste estudo. A influência do processo de relaxação é maior que as tensões desenvolvidas durante a formação dos precipitados. Os nitretos aqui formados também devem possuir forma, distribuição, volume e interface diferente dos formados em temperaturas mais baixas. Próximo à superfície, as tensões são mais baixas, pois o teor de carbono local é menor, devido à redistribuição de carbono, como discutido anteriormente. A profundidade da camada nitretada para a temperatura de $560^{\circ} \mathrm{C}$ é maior, pois o processo de difusão do nitrogênio é maior para uma temperatura de processo mais alta.

Observa-se que, em geral, um aumento na temperatura de nitretação resulta em uma maior profundidade atingida pelas tensões residuais compressivas, porém, as mesmas possuem menor intensidade. Também é possível observar que a

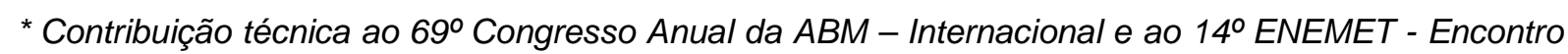
Nacional de Estudantes de Engenharia Metalúrgica, de Materiais e de Minas, 21 a 25 de julho de 2014, São Paulo, SP, Brasil. 


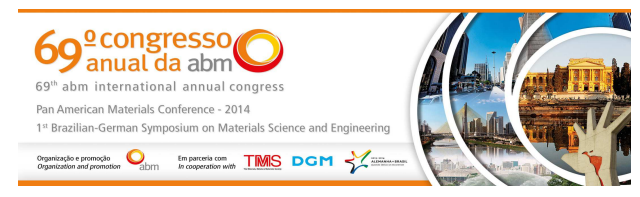

temperatura possui maior influência no perfil de tensão residual do que o fator tempo.

Tabela 3: Influência dos nitretos formados na tensão residual da camada nitretada [18].

\begin{tabular}{c|c|c}
\cline { 2 - 3 } & $\begin{array}{c}\text { Tensão residual } \\
\text { (relativo aos formadores de nitretos) }\end{array}$ & $\begin{array}{c}\text { Tensão residual } \\
\text { (relativo ao } \mathbf{~} \text { ) }\end{array}$ \\
\hline Fases/Nitretos & $\mathrm{MPa}$ & $\mathrm{MPa}$ \\
\hline $\mathbf{F e r r i t a} ; \mathbf{0 , 1} \mathbf{N}$ & - & -2700 \\
\hline $\mathbf{F e}_{\mathbf{4}} \mathbf{N}$ & - & -2600 \\
\hline $\mathbf{A I N}$ & -820 & -1600 \\
\hline $\mathbf{C r N}$ & -440 & -1700 \\
\hline $\mathbf{C r} \mathbf{N}$ & -210 & -1600 \\
\hline $\mathbf{F e}_{3} \mathbf{C}$ dissolvido & - & $+1250^{*}$ \\
\hline${ }^{*}$ em relação ao percentual de C presente nesta fase \\
\hline \multicolumn{2}{|c}{}
\end{tabular}

Nota-se no estudo do efeito do percentual de nitrogênio na atmosfera nitretante a presença de tensões compressivas na superfície, sendo mais intensa e em maior profundidade, quanto maior a quantidade de nitrogênio presente, como mostra a Figura 7. O valor máximo desta tensão encontra-se deslocado para o interior da amostra em maior grau quanto maior o teor de nitrogênio. A partir dos perfis apresentados, observa-se que o máximo das tensões compressivas, para a proporção de nitrogênio de 5\%, está localizado a aproximadamente a $15 \mu \mathrm{m}$ da superfície, tendo pouca intensidade e que, para a curva referente a $40 \%$ de nitrogênio, o máximo valor da tensão compressiva situa-se de 100 a $120 \mu \mathrm{m}$. Apesar de sua localização ser mais profunda, a intensidade é semelhante ao do processo em que se utilizou $20 \%$ de nitrogênio. Outro efeito interessante, observado para o processo utilizando $40 \%$ de nitrogênio, é que próximo a superfície $(0 \mathrm{~mm}$ de profundidade), as tensões compressivas são baixas.

Estes níveis de tensões, encontrados para o material nitretado, utilizando $40 \% \mathrm{~N}_{2}$, podem ser explicados através do mecanismo de precipitação de nitretos, na camada de difusão, como também na forma de camada de compostos.

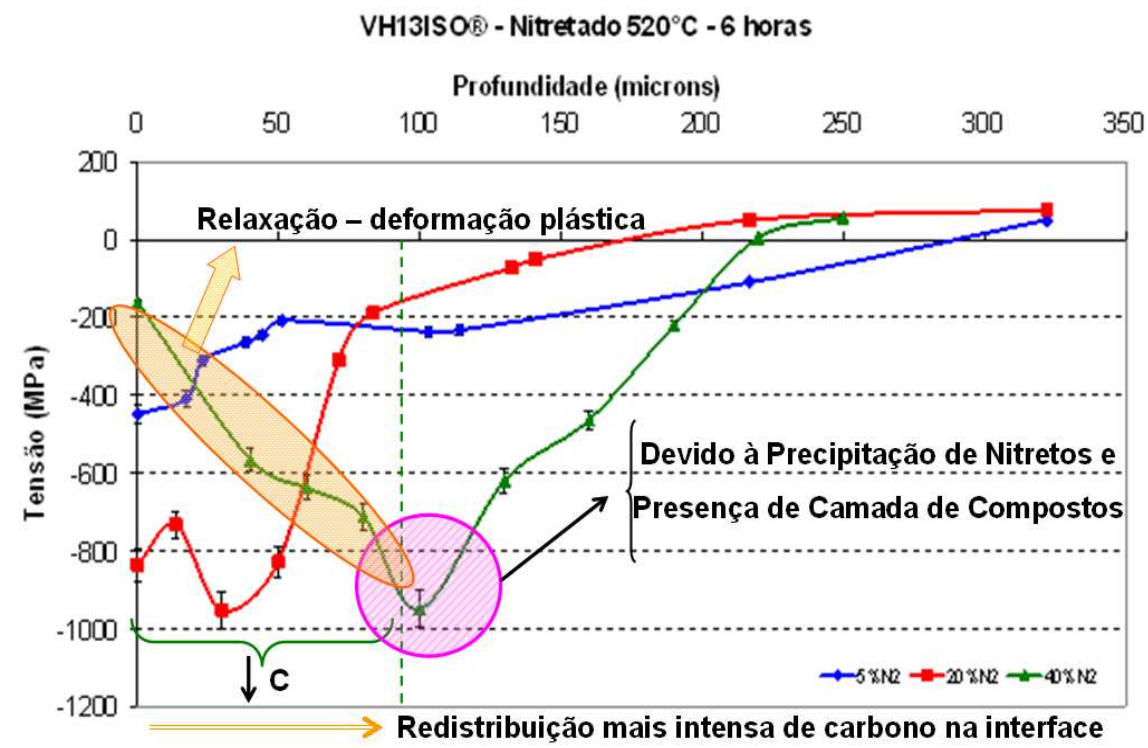

Figura 7: Influência da atmosfera gasosa nas tensões residuais - aço VH13ISO - nitretado por 6 horas e temperatura de $520^{\circ} \mathrm{C}$, para diferentes percentuais de nitrogênio.

* Contribuição técnica ao $69^{\circ}$ Congresso Anual da ABM - Internacional e ao 14ํㅡㄹ ENEMET - Encontro Nacional de Estudantes de Engenharia Metalúrgica, de Materiais e de Minas, 21 a 25 de julho de 2014, São Paulo, SP, Brasil. 


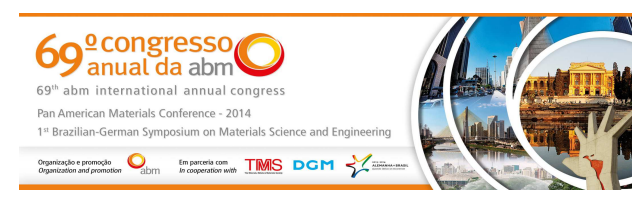

Ao se analisar o efeito da atmosfera gasosa, Figura 7, as tensões residuais de compressão, para a condição contendo $40 \% \mathrm{~N}_{2}$ são resultantes de diversos fatores: início da curva - menor teor de carbono e relaxação por deformações plásticas geradas pela intensidade de tensões da camada de compostos; fim da curva devido à precipitação de nitretos e à formação da camada de compostos. $\mathrm{Na}$ superfície do material, como a quantidade de nitrogênio ultrapassou significativamente 0 limite de solubilidade do nitrogênio na matriz, houve 0 deslocamento do equilíbrio do sistema [23] favorecendo a formação de nitretos do tipo $y^{\prime} e$ e. Uma vez saturado o sistema, houve início da formação de filmes contínuos de nitreto, precipitados não coerentes com a matriz, resultando, posteriormente, a formação da camada de compostos. Como a camada de compostos é constituída basicamente por um filme de nitretos a base de ferro, suas propriedades mecânicas diferem significativamente das do substrato e da camada de difusão (material depositado). Isto resulta em diferentes níveis de tensões, devido também aos diferentes coeficientes de expansão térmica e de condutividade térmica, durante processo de resfriamento do processo de nitretação [18].

Ao se analisar o processo de nitretação onde há formação de camada de compostos, para teores elevados de nitrogênio na atmosfera gasosa, há uma associação de fatores que serão responsáveis pelo nível de tensões residuais:

- descarbonetação da camada superficial: conforme ocorre o processo de nitretação, o carbono desloca-se para o interior do material, fazendo com que a superfície apresente menor quantidade de carbono em solução sólida. Quanto maior a quantidade de nitrogênio inserido no material, mais intenso será este processo. O teor de carbono presente na superfície do material também influencia o nível de tensões residuais: quanto maior, maior será a intensidade da tensão residual de compressão. Como no processo em que se utiliza $40 \% \mathrm{~N}_{2}$ o teor de carbono torna-se menor em regiões próximas à superfície, menor será o nível de tensões residuais de compressão, conforme pode ser visto na Figura 7. Isto também explica o motivo pelo qual o máximo de tensão residual de compressão está mais deslocado para o interior da camada de difusão.

- introdução de nitrogênio em solução sólida e precipitação de nitretos: durante processo de nitretação, quanto maior a quantidade de nitrogênio presente, maior será a quantidade de nitretos formados. A precipitação de nitretos influi significativamente no nível de tensões residuais de compressão, conforme já visto na Tabela 3.

- formação de camada de compostos: a formação de camada de compostos torna-se uma importante fonte de tensões residuais de compressão, uma vez que na etapa de resfriamento, a mesma contrai mais, comparativamente à camada de difusão e ao substrato. Consequentemente, o nível de tensões de compressão será maior. Este evento somado às tensões geradas durante formação de nitretos pode colaborar para que o nível de tensões residuais seja elevado a ponto de proporcionar pequenas deformações plásticas na superfície do material, resultando em relaxações de tensões, reduzindo o nível de tensões residuais resultante.

- presença de combinação de nitretos do tipo $\gamma^{\prime}$ e $\varepsilon$ na camada de compostos: as tensões residuais de compressão gerada para a formação dos nitretos do tipo $\gamma$ ' é cerca de $30 \%$ quando comparada à formação de nitretos do tipo $\varepsilon$.

\footnotetext{
* Contribuição técnica ao 69 Congresso Anual da ABM - Internacional e ao $14^{\circ}$ ENEMET - Encontro Nacional de Estudantes de Engenharia Metalúrgica, de Materiais e de Minas, 21 a 25 de julho de 2014, São Paulo, SP, Brasil.
} 


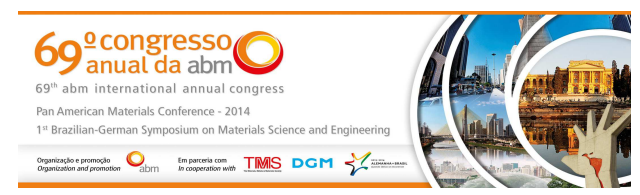

Camadas de compostos contendo maior percentual de nitretos $\varepsilon$, possui menor nível de tensões residuais de compressão.

Ao comparar as imagens obtidas pela Figura 1, com os resultados de tensões residuais e perfis de dureza, pode-se resumir os efeitos da temperatura, tempo e atmosfera gasosa de nitretação, bem como a influencia dos elementos de liga, na Tabela 4.

Tabela 4: Variáveis do processo de nitretação e seus efeitos na dureza, espessura da camada, tensão residual e formação de camada branca.

\begin{tabular}{|c|c|c|c|}
\hline Variável & Tempo & Temperatura & $\% \mathbf{N}_{2}$ \\
\hline Eureito & - & + & ++ \\
Profundidade Camada Nitretada & + & ++ & ++ \\
Formação Camada Branca & - & + & ++ \\
Tensão Residual mais Compressiva & - & +++ & + \\
Profundidade Tensão Residual & - & ++ & ++ \\
\hline \multicolumn{2}{|c|}{-: pouco / +: razoável / ++: muito / +++: muitíssimo } \\
\hline
\end{tabular}

A temperatura mostrou-se bastante importante para o processo de nitretação, tendo forte efeito tanto na profundidade da camada nitretada, quanto na tensão residual. Quando consideramos uma temperatura mais elevada, uma maior quantidade de nitrogênio estará disponível na superfície do material, para promover a difusão, além da difusividade do mesmo ser maior, conforme abaixo:

$$
\text { Equação de Jack e Jack [22] } \rightarrow \xi^{2}=\frac{2[N]}{r[X]} D t-\text { equação } 1 .
$$

Onde D é função de $\exp ^{\frac{-Q}{R T}} \therefore \uparrow T \Rightarrow \uparrow D_{N}$

Se a concentração de nitrogênio atômico, [N], e a difusividade do nitrogênio, D, no material é maior, maior será a profundidade da camada nitretada, $\xi$.

Para temperaturas mais baixas, os átomos de soluto intersticial não são capazes de se mover prontamente, menor difusividade, através da matriz e a sua influência na precipitação de nitretos de ferro, $\mathrm{Fe}_{3} \mathrm{~N}$ e $\mathrm{Fe}_{4} \mathrm{~N}$ será acentuada [22]. Outro efeito também observado é a intensidade da tensão residual compressiva obtida. Para baixas temperaturas, como a difusividade do nitrogênio é menor, ele tenderá a ficar mais restrito nas camadas mais superficiais, causando maiores deformações locais, pela precipitação de nitretos, que possuem maior volume molar que a matriz. Como a temperatura é mais baixa, a quantidade de nitrogênio em solução sólida também será menor [23]. Ao se aumentar a temperatura do processo, além de se aumentar a difusividade do nitrogênio na matriz, uma maior quantidade de nitrogênio entra em solução sólida. Adicionalmente, a exposição a temperaturas maiores ocasiona dois processos: alívio de tensões e coalescimento dos precipitados formados.

A equação 1 permite concluir que o aumento do teor de nitrogênio na atmosfera nitretante, aumenta a profundidade da camada nitretada.

\footnotetext{
* Contribuição técnica ao 69 Congresso Anual da ABM - Internacional e ao 14ํㅡㄹ ENEMET - Encontro Nacional de Estudantes de Engenharia Metalúrgica, de Materiais e de Minas, 21 a 25 de julho de 2014, São Paulo, SP, Brasil.
} 


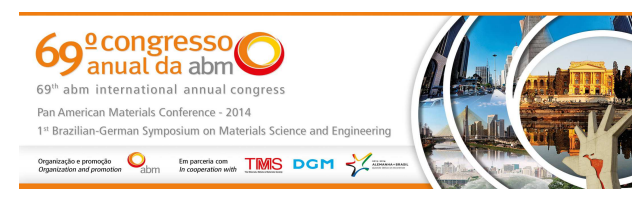

As tensões residuais podem ser consideradas como resultantes de uma associação de fatores, sendo eles:

(a) Tensões residuais intrínsecas $\rightarrow$ ocorrem durante o processo de nitretação e estão relacionadas à:

- Presença de nitrogênio em solução sólida no reticulado da martensita;

- Precipitação de nitretos na camada de difusão, sendo que os mesmos possuem forma, distribuição, tamanho e interface distintas da martensita. Cada tipo de nitreto precipitado possui uma contribuição para a tensão residual de compressão;

- Redistribuição de carbono na camada de difusão.

(b) Tensões residuais extrínsecas $\rightarrow$ ocorrem durante 0 processo de resfriamento e estão relacionadas basicamente à camada de compostos. Durante processo de resfriamento, a camada de compostos por possuir maior contração volumétrica, comparado à camada de difusão e ao substrato, contrai-se desenvolvendo tensões residuais de compressão na superfície do material. Estas tensões serão tanto maiores quanto maior for a temperatura de nitretação.

A escolha dos parâmetros para o processo de nitretação influi no resultado das tensões residuais tanto na camada de difusão, quanto na camada de compostos, visto que podem ocorrer processos de relaxações de tensões por deformações plásticas, em casos onde a temperatura de nitretação é mais elevada, ou em casos em que a camada de compostos possui elevada tensão residual, levando ao processo de deformação plástica sob compressão.

\subsection{Efeito da Temperatura no Alívio de Tensões}

Os resultados referentes ao alívio de tensões e de redução da dureza da camada nitretada, após submeter amostras a $600^{\circ} \mathrm{C}$, por diferentes tempos, são apresentados nas Figuras 8 e 9. Nota-se a expressiva variação das tensões residuais presentes na camada nitretada, logo que o material é submetido por 30 minutos em temperatura de $600^{\circ} \mathrm{C}$. Entretanto, o perfil de microdureza não é tão intensamente influenciado por exposição à temperatura, por diversos tempos, como mostra a Figura 9. Tal efeito pode ser atribuído a processos de alívio de tensões, sem alteração dos precipitados formados.

Ao se prolongar o tempo em elevada temperatura, não somente o nível de tensões é reduzido, como também a dureza da camada nitretada, bem como a dureza do material base começa a ser afetado pelo processo, num mecanismo de perda de dureza a quente.

A consequência prática desses resultados é que após a superfície da matriz ser exposta a inúmeras ciclagens térmicas, as tensões residuais são aliviadas por mecanismos de recuperação/eliminação de defeitos cristalinos, redução do numero de discordâncias. O fenômeno observado é interessante, uma vez que pode ser utilizado na indústria para explicar os mecanismos de fadiga térmica, bem como predizer em qual etapa do processo será necessário realizar processo de recuperação da superfície por rebaixamento, ou até mesmo um novo processo de nitretação.

Baseado nas Figuras 8 e 9, é possível dizer que para os primeiros ciclos de injeção de alumínio, há dois mecanismos responsáveis por retardar a nucleação das trincas térmicas:

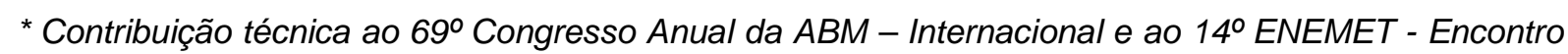
Nacional de Estudantes de Engenharia Metalúrgica, de Materiais e de Minas, 21 a 25 de julho de 2014, São Paulo, SP, Brasil. 


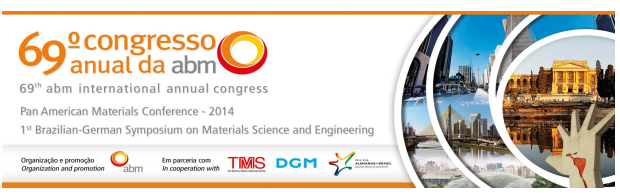

(i) presença de tensões residuais de compressão na superfície do material região que ficará em contato com o alumínio líquido;

(ii) maior dureza local, o que proporciona maior resistência mecânica local, retardando as deformações plásticas.

Assim, se considerarmos que em cada ciclo o material é exposto a altas temperaturas (acima de $600^{\circ} \mathrm{C}$ ), por 2 a 5 segundos, pode-se estimar que a tensão de compressão atue em até 5.000 peças injetadas. Para os estágios mais avançados do processo de injeção (acima de 5.000 peças injetadas), o mecanismo atuante é a maior dureza local, uma vez que as tensões residuais já não são mais significativas. Tempos prolongados de exposição em temperaturas elevadas causam redução de dureza do substrato, como seve na Figura 9, para o tempo de 100 horas.

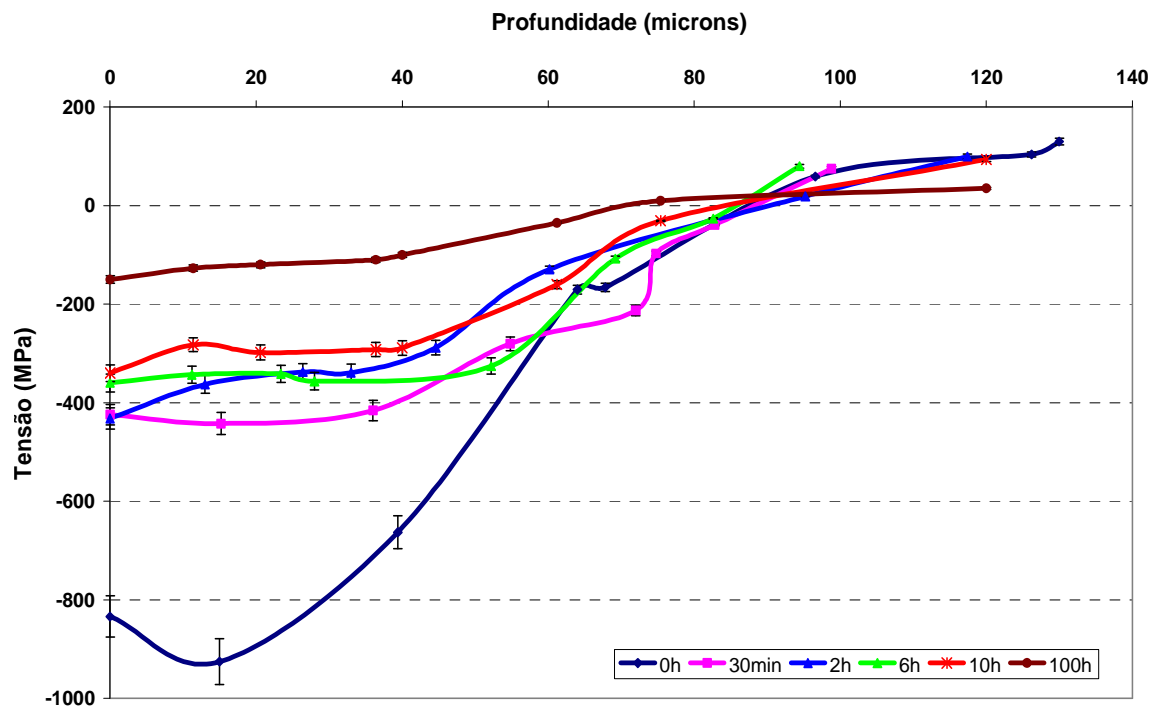

Figura 8: Tensões residuais na superfície do aço $\mathrm{VH} 13 \mathrm{ISO} \mathrm{O}^{\circledR}$ nitretado em temperatura de $520^{\circ} \mathrm{C}$, por 6 horas e atmosfera gasosa $20 \% \mathrm{~N}_{2}+80 \% \mathrm{H}_{2}$, após ser submetido a temperatura de $600^{\circ} \mathrm{C}$, por vários tempos.

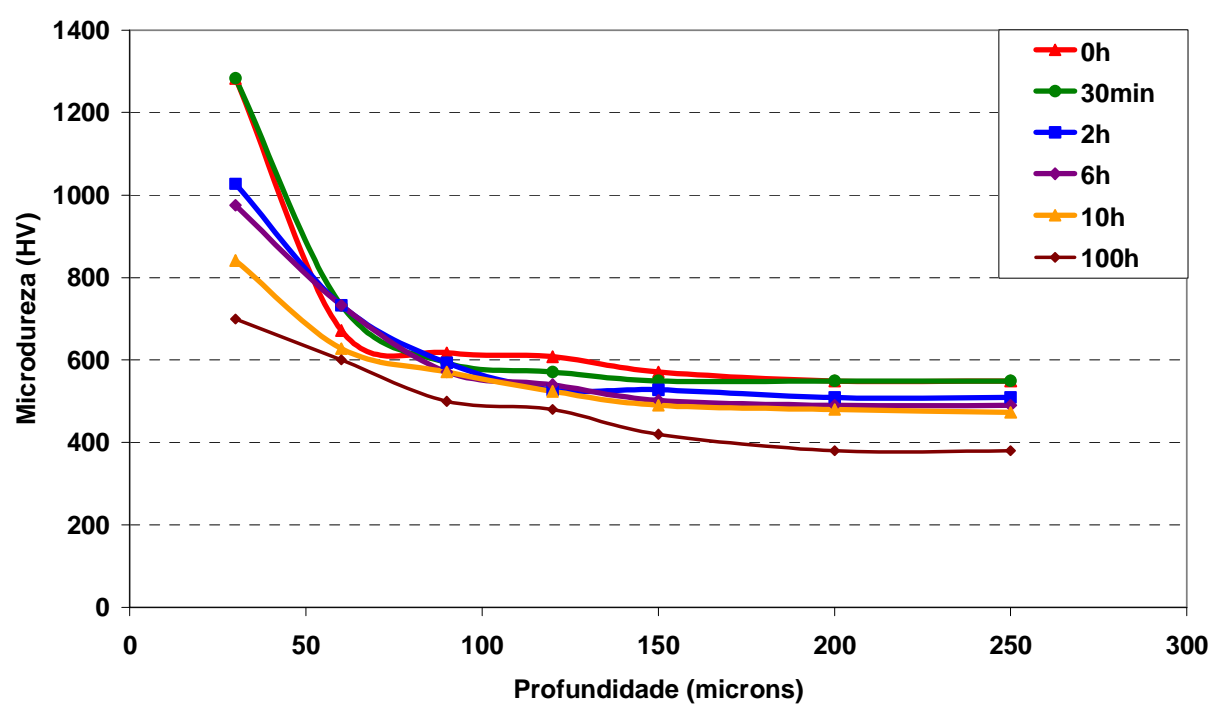

Figura 9: Perfil de dureza na superfície do aço $\mathrm{VH} 131 \mathrm{SO}^{\circledR}$ nitretado em temperatura de $520^{\circ} \mathrm{C}$, por 6 horas e atmosfera gasosa $20 \% \mathrm{~N}_{2}+80 \% \mathrm{H}_{2}$, após ser submetido a temperatura de $600^{\circ} \mathrm{C}$, por vários tempos.

\footnotetext{
* Contribuição técnica ao 69 Congresso Anual da ABM - Internacional e ao 14ํㅡㄹ ENEMET - Encontro Nacional de Estudantes de Engenharia Metalúrgica, de Materiais e de Minas, 21 a 25 de julho de 2014, São Paulo, SP, Brasil.
} 


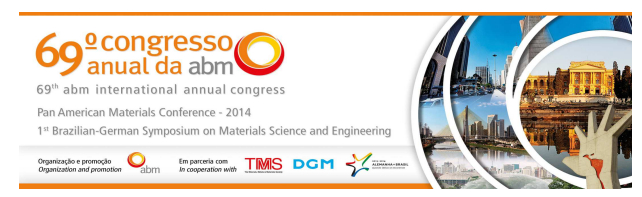

\section{CONCLUSÕES}

- A variação dos parâmetros de nitretação: tempo, temperatura e percentual de nitrogênio, afetam o perfil de dureza e de tensões residuais presentes na camada nitretada, bem como seus microconstituintes:

i) quanto maior o tempo, maior é a profundidade da camada nitretada e mais deslocado para o interior da camada nitretada estará o poço de máxima tensão residual de compressão. Para tempos mais longos, ocorre a formação de camada de compostos;

ii) quanto maior a temperatura, maior é a profundidade da camada nitretada. Quanto menor a temperatura de nitretação mais próximo da superfície se encontra o poço de tensão residual. Para temperaturas mais baixas, ocorre a formação de camada de compostos. O máximo de tensão residual de compressão foi encontrado para a menor temperatura, saindo de valor da ordem de $-600 \mathrm{MPa}$ para temperatura de $560^{\circ} \mathrm{C}$, atingindo valores de -2000 a $-2500 \mathrm{MPa}$ para a temperatura de $480^{\circ} \mathrm{C}$;

iii) quanto maior o percentual de nitrogênio na atmosfera gasosa, maiores são a dureza e a profundidade da camada nitretada, bem como mais deslocado para o interior do material nitretada se encontra o poço de máxima tensão residual de compressão.

- O material nitretado, após ser submetido a temperatura elevadas, apresenta redução no nível de tensões residuais de compressão, ocorrendo processo de alívio de tensões. O mesmo efeito não é tão fortemente verificado no perfil de dureza do material. Deste modo, é possível dizer que para os primeiros ciclos de injeção de alumínio, há dois mecanismos responsáveis por retardar a nucleação das trincas térmicas:

(i) presença de tensões residuais de compressão na superfície do material;

(ii) maior dureza local, dada pela maior dureza a quente existente no perfil de dureza da camada nitretada.

\section{REFERÊNCIAS}

1 Haddad P, Gonçalves CS. O Uso de Aços Especiais em Matrizes de Fundição - Revista Siderurgia Brasil, out. 2010, pags, 46 a 49.

2 Malm S, Tidlund J. Increased Life for Die Casting Dies - Transactions of the Tenth International Die Casting Congress, 1979, pag 1-14 - Society of Die Engineers.

3 Srivastava A, Joshi V, Shivpuri R. Computer Modeling and Prediction of Thermal Fatigue Cracking in Die-Casting Tooling. Wear, 2004 - pag. 38-43.

4 Mesquita RA, Haddad P. Propriedades Fundamentais dos Aços Ferramenta para Matrizes de Forjamento. XII Conferência Internacional em Forjamento, 2009.

5 Pinedo CE. Nitretação por Plasma, Anais do I Seminário Internacional de Engenharia de Superfície, Ed. Núcleo de Pesquisas Tecnológicas da Universidade de Mogi das Cruzes, pp.: 13-26, 1995.

6 Pellizzari M, Molinari A, Straffelini G. Thermal Fatigue Resistance of Plasma DuplexTreated Tool Steel. Surface \& Coatings Technology, 2001; 142: 1109-1115.

7 Spies HJ, Vogt F, Svennon G. Neue Hütte 28 (1983).

8 Malm S, Norström A. - Material-Related Model for Thermal Fatigue Applied to Tool Steels in Hot-Work Applicatons. Metal Science, September 1979, pag. 544-550.

9 Young RM, Morre AA. Thermal Fatigue of Die Steels: A Brief Summary and Perspective. Industrial Heating - July, 1981, pag 24-27.

* Contribuição técnica ao $69^{\circ}$ Congresso Anual da ABM - Internacional e ao 14ํㅡㄹ ENEMET - Encontro Nacional de Estudantes de Engenharia Metalúrgica, de Materiais e de Minas, 21 a 25 de julho de 2014, São Paulo, SP, Brasil. 


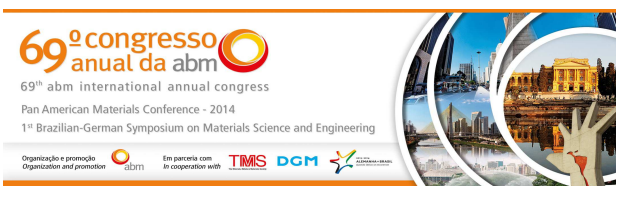

10 Ferreira GEF. Avaliação da resistência à fadiga térmica do aço H13 nitretado pelos processos gasoso e por plasma, Universidade Federal de Santa Catarina, 2001.

11 North American Die Casting Association. NADCA\#207-2008: Special Quality Die Steel \& Heat Treatment Acceptance Criteria for Die Casting Dies. Wheeling, IL: NADCA, 2008.

12 Roberts G, Krauss G, Kennedy R. Tool Steels. 5. ed. Materials Park, Ohio: ASM International, 1998. p. 1-123 e p. 219-250.

13 Persson A, Hogmark S, Bergström J. Temperature Profiles and Conditions for Thermal Fatigue Cracking in Brass Die Casting Dies. Materials Processing Technology 152, 2004, pag. 228-236.

14 Mesquita RA, Barbosa CA. Failure Analysis in Tool Steels, p. 311-355. In: Canale LCF, Mesquita RA, Totten GE. Failure Analysis of Heat Treated Steel Components. Ohio: American Society for Metals, 2008.

15 Pellizzari M, Molinari A, Straffelini G. - Thermal Fatigue Resistance of Gas and Plasma Nitrided 41CrAIMo7 Steel. Materials Science and Engineering A352, 2003, pag. 186-194.

16 Wolpi DJ. Understanding How Components Fail $-A S M-2^{\text {nd }}$ edition, Chapter 7, pag. 6383.

17 Birol Y., Effect of post-oxidation treatment on thermal fatigue behaviour of plasma nitrided hot work tool steel at elevated temperatures. Surface \& Coatings Technology 205, pag 2763-2769, 2011.

18 Kolozsváry Z, PLASMATERM S.A., S.C., Tg-MURES, ROMANIA . Residual Stresses in Nitriding. In: Handbook of Residual Stress and Deformation of Steel. Materials Park, $\mathrm{OH}$ : ASM, 2002. p.209-219.

19 Hirsch TK, et al. Residual Stress-Affected Diffusion during Plasma Nitriding of Tool Steels. Metallurgical and Materials Transactions. v.35 A, p.3523-3530. Nov. 2004.

20 Djeghlal ME, Barrallier L. Influence of alloying elements ( $\mathrm{Cr}, \mathrm{Mo}, \mathrm{V})$ on nitrides residual stresses generated during the nitriding of synthetic iron alloys. Annales de Chimie Science des Matériaux, v.28, n. 1, p. 43-52. Jan. 2003.

21 Arimoto K. et al. Development of simulation tool for predicting distortion and residual stress in nitrided parts. In: International conference on distortion engineering, 2. Sep. 2008. Bremen, Germany. Proceedings... Bremen: IWT, 2008. p.461-470.

22 Jack DH, Jack KH. Carbides and Nitrides in Steel. Materials Science and Engineering, 1973; 11: 1-27.

23 Lehrer E. Z. Elektrochem, V. 36, p. 383, 1930.

\footnotetext{
* Contribuição técnica ao 69 Congresso Anual da ABM - Internacional e ao $14^{\circ}$ ENEMET - Encontro Nacional de Estudantes de Engenharia Metalúrgica, de Materiais e de Minas, 21 a 25 de julho de 2014, São Paulo, SP, Brasil.
} 